\title{
Developing a creative method for reuse of clothing
}

\author{
Magdalena Pavlova ${ }^{1,{ }^{*}}$, and Radka Atanasova ${ }^{1}$ \\ ${ }^{1}$ Technical University of Sofia, Department of Textiles, 1000 Sofia, Bulgaria
}

\begin{abstract}
The article proposes a creative method for reducing textile waste from the sewing industry. A street fashion collection of denim clothing has been created. A combination of three approaches was used: the concept of a capsule wardrobe when selecting the types and styles of clothing in the collection; upcycling as an idea for reusing sewing products; a moulage draping method in developing patterns of the garment. To confirm the results, physical samples of the products were sewed. The proposed approach develops the creative thinking of the designer and individual skills of the clothing pattern maker. The anti-consumer attitude of clothing customers to the planet's resources is being nurtured. The effect is also enhanced by the focus on denim products, whose production is one of the largest in the textile industry. The approach opens up a market niche with the ability to set up a small business online.
\end{abstract}

\section{Introduction}

The fashion industry is the world's second-most polluting industry after oil industry. The phenomenon is a consequence of the uncontrolled cultivation of plant and animal species for raw materials, the production of artificial and synthetic textile materials, the pollution of soil and water. At the same time, levels of consumerism among customers are rising, driven by marketing strategies in the fashion industry, generating millions of tons of textile waste.

Significant reduction of textile waste from the sewing industry can be achieved by using a combination of three approaches in the design and manufacture of a fashion collection: the concept of "capsule wardrobe" when choosing types and models of clothing in the collection, "upcycling" as an idea for reuse of garments and moulage modelling method in the development of clothing patterns.

The "capsule wardrobe" concept was introduced in the 1970s by Susie Foe, owner of the London boutique Wardrobe [4]. The capsule collection consists of several basic types of clothing (5 to 12 ), which do not go out of fashion and can be combined with each other, and subsequently complemented with fashionable seasonal accessories. The idea was popularized by the American designer Donna Karan, who in 1985 presented an impressive capsule collection of seven interchangeable clothes under the name "7 Easy Pieces". The capsule wardrobe is structured thematically - a capsule for everyday life, for the office, for formal occasions, for sports, etc.

\footnotetext{
*Magdalena Pavlova: mpavlova@,tu-sofia.bg
} 
The "upcycling" method, on the other hand, is associated with creative reuse of the product. This increases the value of the original product by changing and/ or adding a personal view to the design of an already manufactured and used product [6]. In "upcycling" a circled economic model is applied. Resources are used for as long as possible. The greatest value is derived from the products. They are recovered several times, unlike the linear economy, which consists of buying, using and disposing of goods as waste. In the United States alone, $85 \%$ of textile waste is recyclable [5]. Big fashion companies create "fast" fashion, "buy - wear - throw away" and have a huge contribution to textile waste pollution.
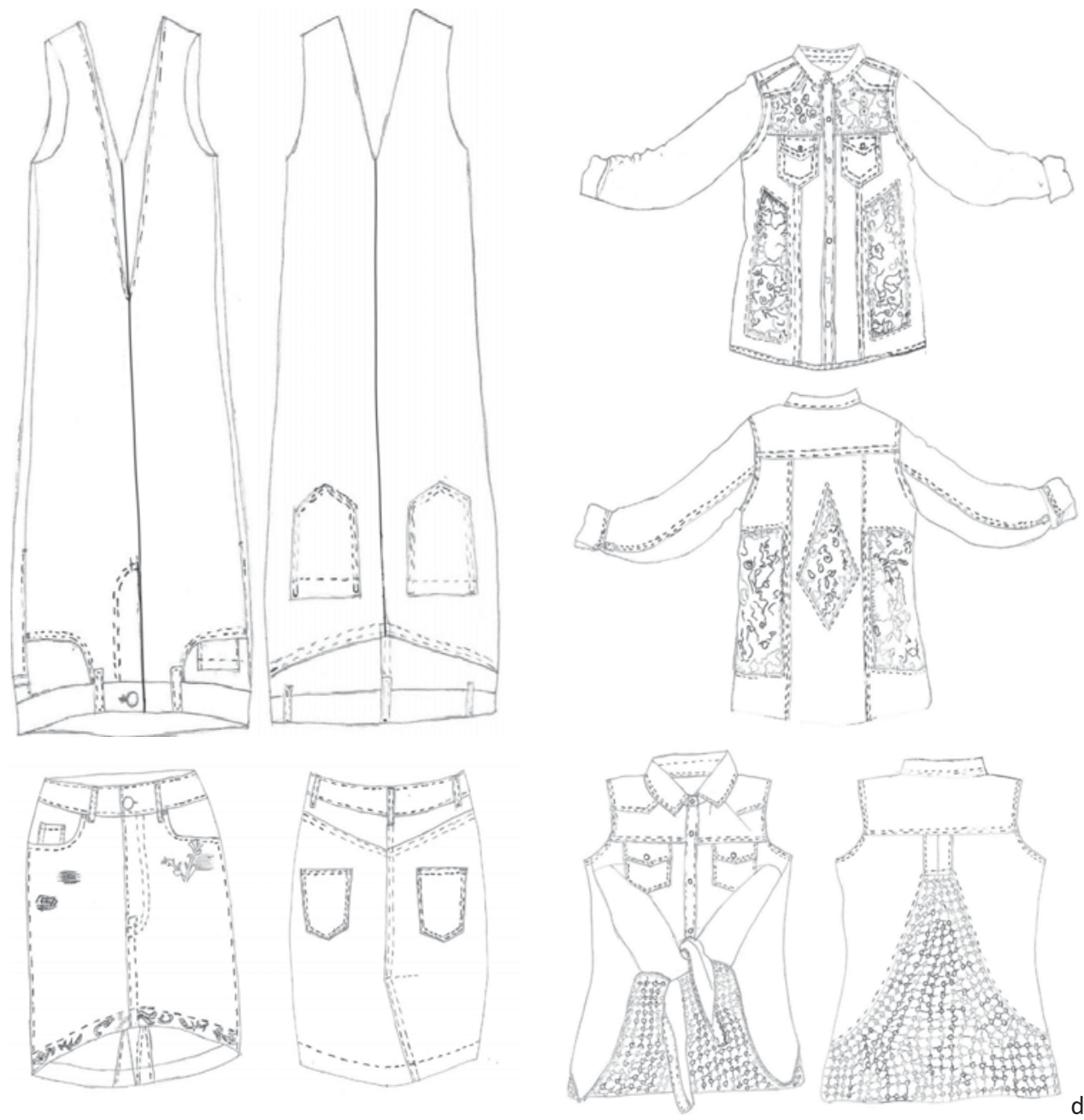

Fig. 1. Fashion sketches of some of the garments from the designed capsule street collection.

"Upcycling" as a method of clothing transformation is one of the solutions for sustainable living and leads to the following positive results: reduction of environmental pollution, reduction of losses in the textile industry and consumerism; fuller use of resource capacity and longer product life cycle; creation unique products and starting a business with a small investment; opening a new field for the development of creative potential of fashion designers. The application of a moulage draping method to develop the patterns of the garment adds mastership and artistic taste to the reuse of the garment. 


\section{Methods and Results}

The combined approach proposed in the present study, for the creative reuse of clothing, is illustrated by the creation of a lady's capsule street collection of "denim" type fabric, containing top and bottom garments. Seven denim basic models of apparel have been upcycled- two shirts and trousers each, two skirts, a knitted vest. Technical sketches of some of the products in the fashion collection are presented on Fig. 1/a-d.

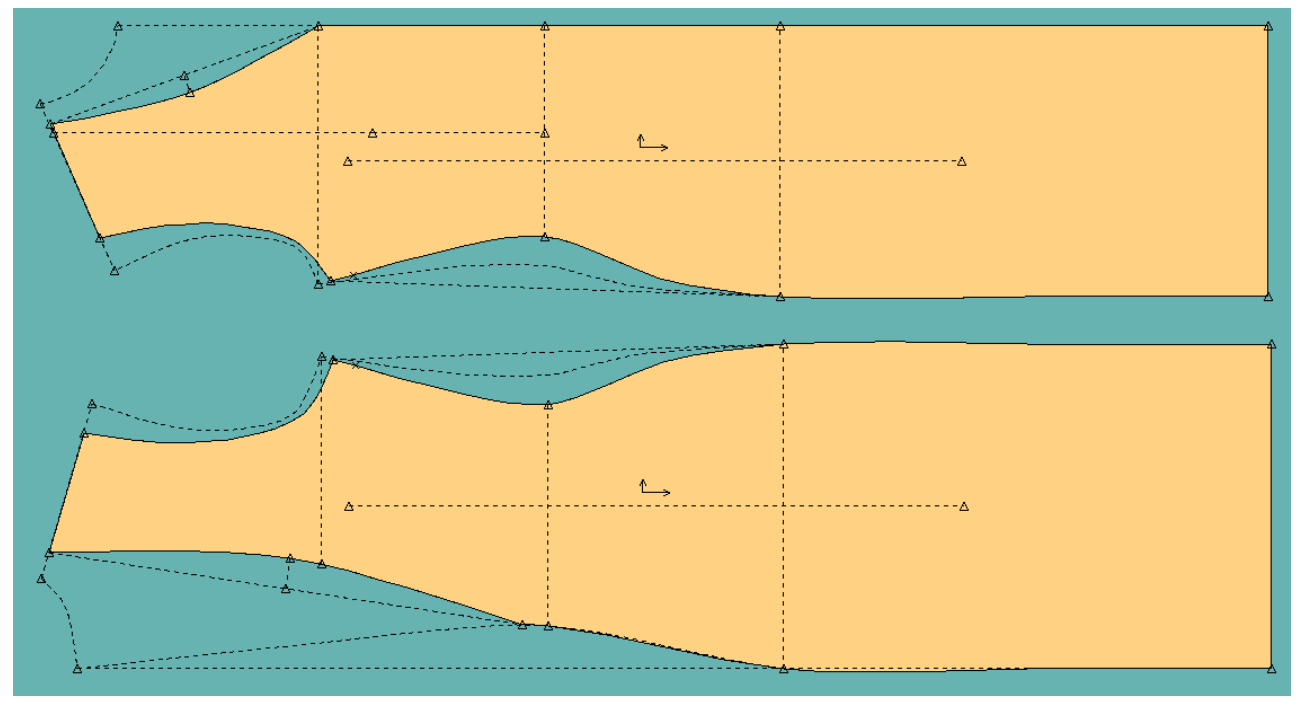

Fig. 2. Pattern making of the lady's dress without sleeves.

The patterns of the garments in the collection are developed on the principle of combining between a base, built by a classical computational-analytical method, and modeling by the moulage method, following the principle of "upcycling", with additional use of textile waste. A method is applied, in which the product to be transformed, is primarily modeled on the pattern basic construction, and then reshaped directly on the torso, according to the given fashion sketch. Direct cutting, outlining, fixing with pins and rough sewing are made. Determining in this case are the experience and individual skills of the pattern maker. Fine reshaping and adjusting is done after undressing the garment. After that it is put on again to make corrections, if necessary. The cycle is repeated until the desired result is achieved. Accepted corrections are fixed by stitches, according to the selected technology.

The approach of work is illustrated on the basis of one of the seven garments in the capsule collection- a lady's dress without sleeves. The style of the dress is presented with a technical sketch of Fig. 1a. In the front and back piece there is a V-neck, strongly deepened on the back. Below the hip line at the front are positioned in an inverted version (with the opening down), two outside sewn pockets, and at the back - two side pockets with arched openings. The triangular yoke in the front of the dress has a pointed end to the openings in the pockets. Zipper fastening plays the role of a slit in the middle seam of the back. The belt with the loops forms the line of the hem. The dress is without sleeves with a slightly deepened armhole. The clothing is developed by transforming lady's denim trousers with an elastomer component (Fig. 3a).

The lady's denim dress with an elastomer component fits tightly to the body, so the construction of lady's clothing made of elastic materials and without darts is chosen as the basic construction. The patterns are worked out for a female figure, standard size 44 
(164/88/96) and have no seam allowance. The horizontal structural sections are calculated with significantly reduced, but with a positive value ease: Waist ease $=0.25 \mathrm{~cm}$, Shoulder ease $=1.75 \mathrm{~cm}$, Waist length ease $=1.5 \mathrm{~cm}$. Their value is compatible with the permissible pressure on the body. There are no chest ease and hip ease to fit the product tightly to the body. The functional relations for calculating the pattern dimensions are according to [1] The fitting value in the middle seam of the back is $3.5 \mathrm{~cm}$.

The functions [3] of the specialized clothing CAD program AccuMark, version V10 of the company Gerber Technology, USA were used for the pattern making. An algorithm for automated construction has been developed. In the modeling process, the end shoulder point was moved inwards along the shoulder line by $2.5 \mathrm{~cm}$, the width of the shoulders was reduced to $10.0 \mathrm{~cm}$, the armhole was deepened by $1.0 \mathrm{~cm}$ along the side seam. The neckline at the front is formed by a smooth curved line with an auxiliary perpendicular $1.5 \mathrm{~cm}$ long. For the back this value is $2.5 \mathrm{~cm}$ and the neckline is open up to $4.0 \mathrm{~cm}$ above the waistline. The finished patterns of the model are presented in Fig. 2. They are used as a starting point for moulage draping.

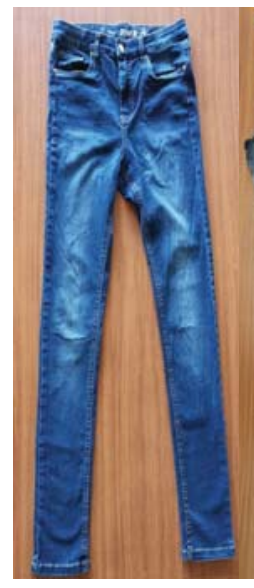

a

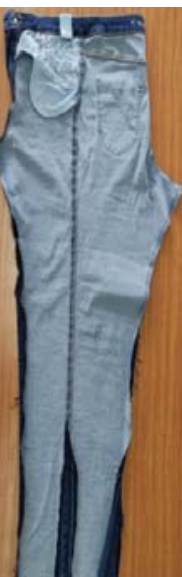

b

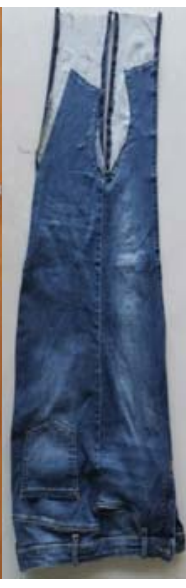

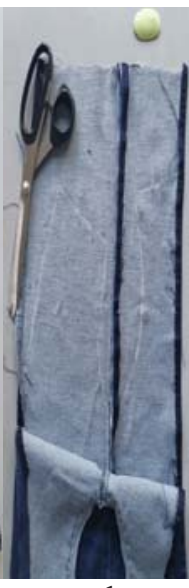

d

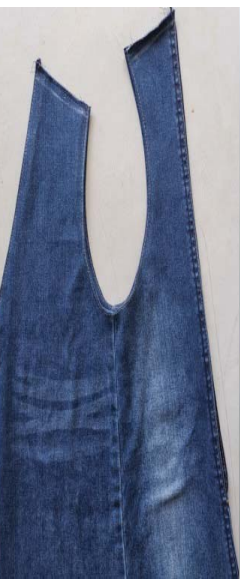

e

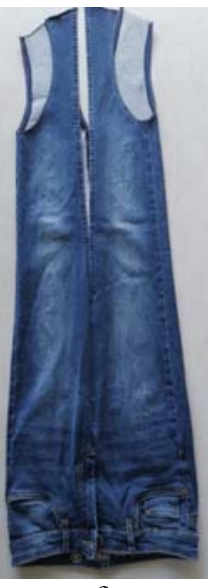

f

Fig. 3. Photos of selected stages of the sequence for transforming the pants into a lady's dress.

The "upcycling" transformation of the garment into a lady's dress is illustrated by the photo material of Fig. 3/ a-f [2]. The original product - lady's denim pants, is shown in Fig. 3a. The sequence for transformation and production of the lady's dress from the collection is presented in details in Table 1. A physical sample of the developed lady's dress is presented in Fig. 4. The dress is worn on a live mannequin, Fig. 4a- full face and at the back with an open slit on Fig. 4b.

Table 1. Technological sequence map for transforming and manufacture a lady's dress.

\begin{tabular}{|c|c|c|c|c|}
\hline & $\begin{array}{c}\text { Name of the } \\
\text { operation }\end{array}$ & Symbol & $\begin{array}{c}\text { Stitch } \\
\text { type }\end{array}$ & Comments \\
\hline $\mathbf{1}$ & $\mathbf{2}$ & $\mathbf{3}$ & $\mathbf{4}$ & $\mathbf{5}$ \\
\hline $\mathbf{1}$ & $\begin{array}{c}\text { Marking the areas for opening crotch } \\
\text { seam, side seams and inside leg seams }\end{array}$ & $\square$ & Handwork & $\begin{array}{c}\text { On the basic } \\
\text { model of lady's }\end{array}$ \\
\hline $\mathbf{2}$ & $\mathbf{2}$ & $\mathbf{3}$ & $\mathbf{4}$ & $\mathbf{5}$ \\
\hline & & & & $\begin{array}{c}\text { trousers acc. to } \\
\text { patterns on Fig. 2 }\end{array}$ \\
\hline $\mathbf{2}$ & Unstitching the above mentioned seams & $X$ & Handwork & Symmetrically \\
\hline
\end{tabular}




\begin{tabular}{|c|c|c|c|c|}
\hline & next to the markings & & & \\
\hline 3 & $\begin{array}{l}\text { Moulage modelling and defining the } \\
\text { length of the opening the seams }\end{array}$ & & Handwork & $\begin{array}{l}\text { On the body or } \\
\text { torso }\end{array}$ \\
\hline 4 & Fastening the opened seams & 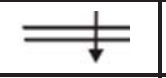 & $\begin{array}{l}\text { Lockstitch } \\
301\end{array}$ & With bar-tack \\
\hline 5 & $\begin{array}{l}\text { Sewing (closing) the openings of the side } \\
\text { pockets }\end{array}$ & & $\begin{array}{l}\text { Lockstitch } \\
301\end{array}$ & $\begin{array}{l}\text { With bar-tack at } \\
\text { both ends of the } \\
\text { side pockets }\end{array}$ \\
\hline 6 & Cutting the bags of the side pockets & $\bar{x}$ & Handwork & $\begin{array}{l}\text { Width of the seam } \\
\text { allowance } 0,3 \mathrm{~cm}\end{array}$ \\
\hline 7 & $\begin{array}{c}\text { Outlining and cutting at the area of crotch } \\
\text { back and front seam under the fastening } \\
\text { zipper }\end{array}$ & & Handwork & $\begin{array}{c}\text { On the basic } \\
\text { model acc. to } \\
\text { patterns on Fig. } 2\end{array}$ \\
\hline 8 & Shaping and adjusting the armhole & & Handwork & $\begin{array}{l}\text { On the body or } \\
\text { torso }\end{array}$ \\
\hline 9 & $\begin{array}{l}\text { Correctly outlining the curves of the } \\
\text { armhole and cutting the contour }\end{array}$ & & Handwork & $\begin{array}{c}\text { On the basic } \\
\text { model acc. to } \\
\text { patterns on Fig. } 2\end{array}$ \\
\hline 10 & $\begin{array}{l}\text { Final shaping and adjusting } \\
\text { the V-neckline and the armhole }\end{array}$ & & Handwork & $\begin{array}{l}\text { On the body or } \\
\text { torso }\end{array}$ \\
\hline 11 & $\begin{array}{l}\text { Tracing the shaped and cuted } \\
\text { symmetrically contours of the neckline } \\
\text { and the armhole }\end{array}$ & & Handwork & $\begin{array}{c}\text { On the basic } \\
\text { model acc. to } \\
\text { patterns on Fig. } 2\end{array}$ \\
\hline 12 & Shaping the shoulders & & Handwork & $\begin{array}{l}\text { On the body or } \\
\text { torso }\end{array}$ \\
\hline 13 & $\begin{array}{l}\text { Oversewing the front neckline, deeped } \\
\text { back neckline, side seams and armholes }\end{array}$ & & $\begin{array}{l}\text { Overedge } \\
504\end{array}$ & \\
\hline 14 & $\begin{array}{l}\text { Turning back and pressing the seam } \\
\text { allowance along the front neckline, back } \\
\text { neckline and armholes }\end{array}$ & $\perp$ & Steam iron & \\
\hline 15 & $\begin{array}{l}\text { Making a decorative seam along the front } \\
\text { neckline, deeped back neckline and } \\
\text { armholes }\end{array}$ & O & $\begin{array}{l}\text { Lockstitch } \\
\quad 301\end{array}$ & Without bar-tack \\
\hline 16 & Final shaping of the shoulders & & Handwork & $\begin{array}{l}\text { On the body or } \\
\text { torso }\end{array}$ \\
\hline 17 & Oversewing the shoulders & -0 & $\begin{array}{c}\text { Overedge } \\
504\end{array}$ & \\
\hline 18 & Sewing the shoulder seams & $\neq 1=8$ & $\begin{array}{l}\text { Lockstitch } \\
301 \\
\end{array}$ & With bar-tack \\
\hline 19 & $\begin{array}{l}\text { Pressing the shoulder seam allowance } \\
\text { open from the wrong side of the dress }\end{array}$ & $\frac{1}{\infty e-0}$ & Steam iron & \\
\hline 20 & $\begin{array}{l}\text { Cutting the seam allowance of the } \\
\text { shoulder seams }\end{array}$ & X & Handwork & Turn-back corner \\
\hline 21 & $\begin{array}{l}\text { Pressing the side seam allowance open } \\
\text { from the wrong side of the dress }\end{array}$ & $\frac{1}{\infty+0}$ & Steam iron & \\
\hline 22 & Threads and chalk cleaning & & Handwork & \\
\hline 23 & Final ironing & $\perp$ & Steam iron & \\
\hline
\end{tabular}




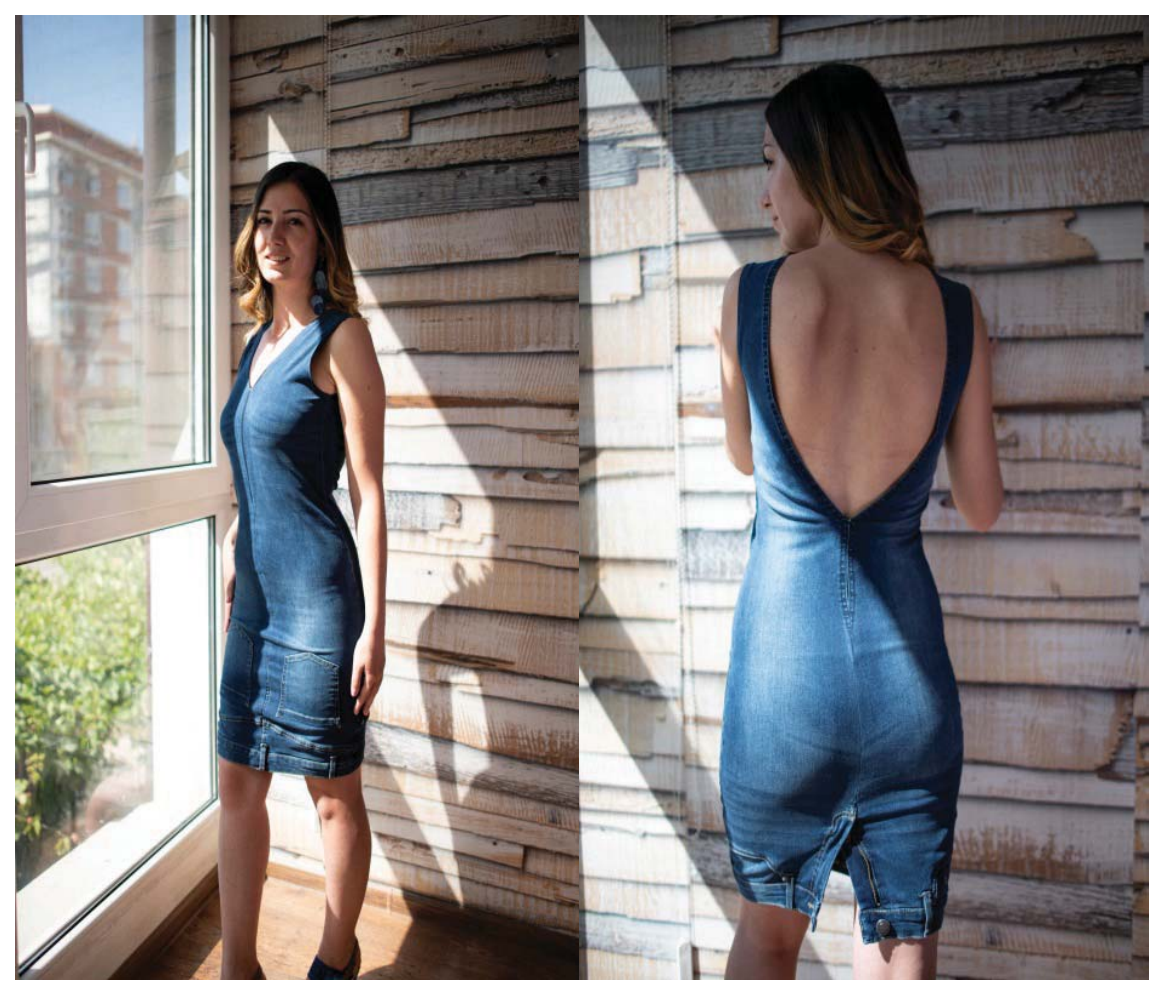

Fig. 4. Photos of the lady's dress, developed by the "upcycling" method

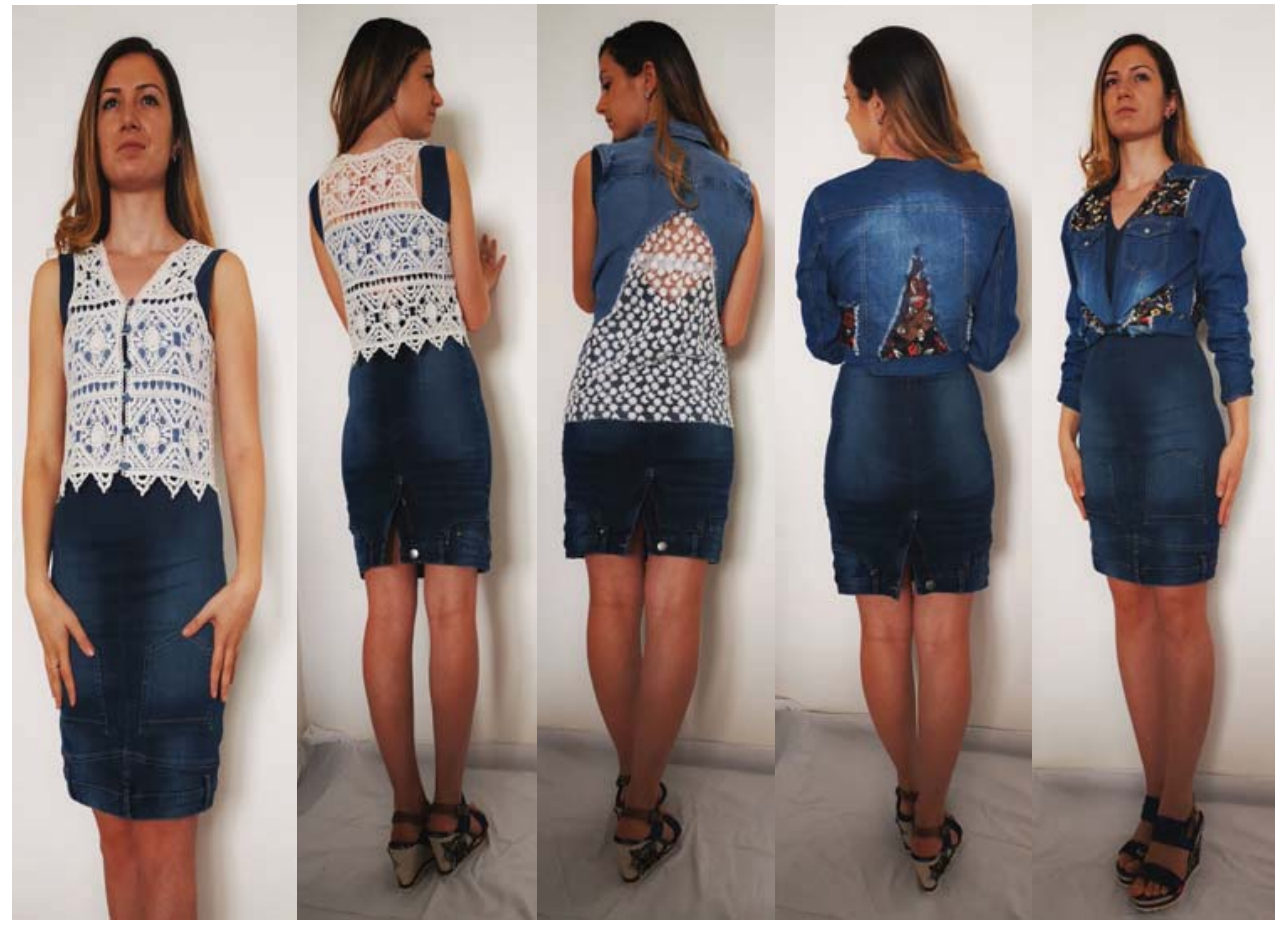

Fig. 5. Combinations of the lady's dress, developed by the "upcycling" method, with products and accessories from the capsule collection. 
On Fig. 5 and Fig. 6 are illustrated some of the many possible combinations between the garments in the capsule street collection, designed according to the developed approach. On Fig. 5 are offered combinations of the lady's dress, developed in the article, with products and accessories, made for the capsule collection. On Fig. 6 some of the garments and accessories are combined with a lady's mini skirt from the collection, with a hem in the form and decorations.

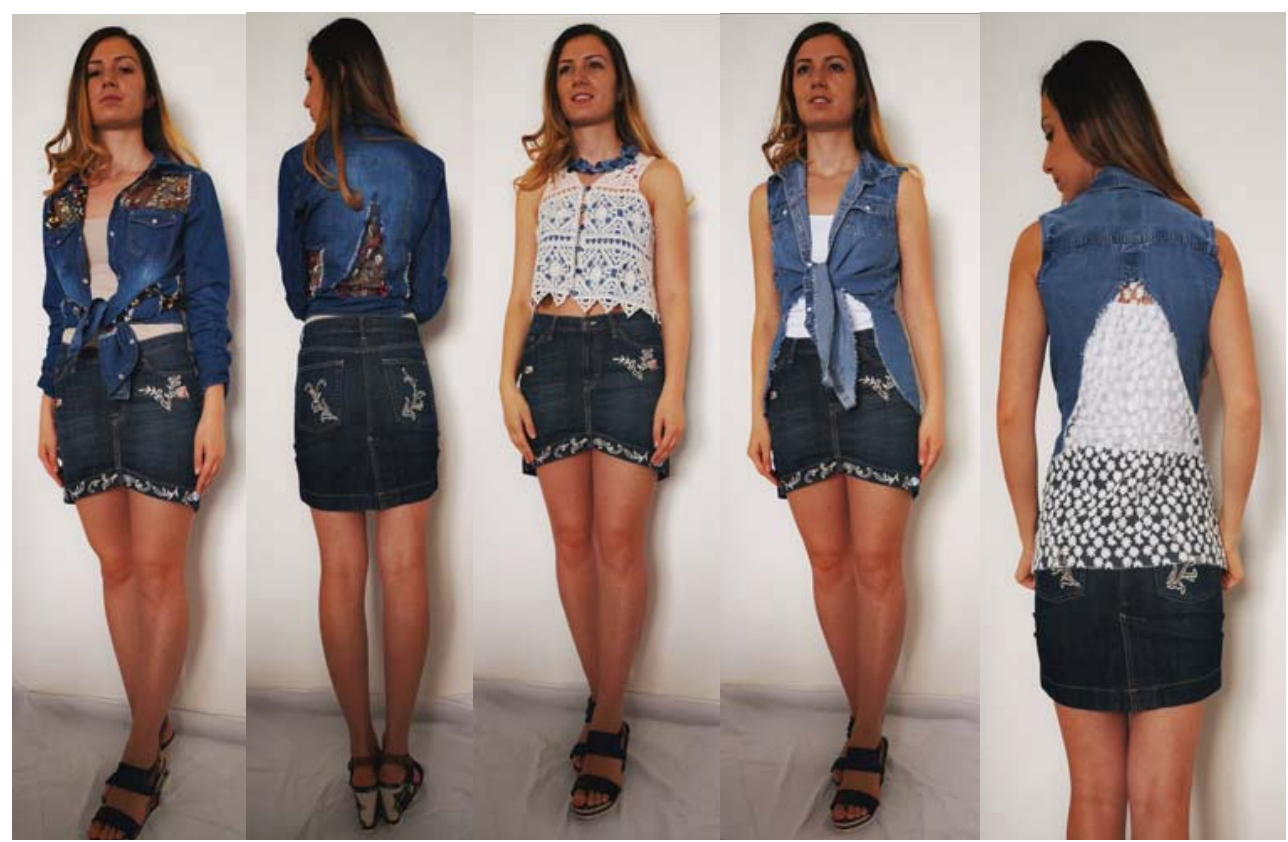

Fig .6. Combinations of the lady's skirt, developed by the "upcycling" method, with products and accessories from the capsule collection

\section{Conclusions}

The article proposes a creative method for reducing textile waste from the sewing industry. A unique fashion collection of denim clothing has been created. A combination of three approaches was used: the concept of a capsule wardrobe when selecting the types and styles of clothing in the collection, "upcycling" as an idea for reusing sewing products; a moulage draping method in developing patterns of the garment. To confirm the results, physical samples of the products were sewed.

The proposed approach develops the creative thinking of the designer and the individual skills of the clothing pattern maker. The anti-consumer attitude of clothing customers to the planet's resources is being nurtured. The effect is also enhanced by the focus on denim products, whose production is one of the largest in the textile industry. The approach opens up a market niche with the ability to set up a small business online.

\section{References}

1. H. Petrov, R. Atanasova, Design of women's clothing from elastic materials, Scientific conference of PEPM'2005, Proceedings, 2, p.p. 153-160, Varna (2005) 
2. F. Yumer, Design of a street collection type "capsule wardrobe" using the principle of upcycling, Diploma thesis, Sofia (2019)

3. User's guide AccuMark Professional Edition V10.0, Gerber Technology Inc., a Business Unit of Gerber Scientific International (2015)

4. https://krasota.rozali.com/modni-saveti/kapsulen-garderob.html, Accessed on date 30 October, 2020

5. https://textilebeat.com/wp-content/uploads/2014/12/Global-apparel-fibre-consumptionvs-population-FINAL.jpg, Accessed on date 30 October, 2020

6. https://intercongreen.com/2010/02/17/recycling-vs-upcycling-what-is-the-difference/, Accessed on date 30 October, 2020

7. https://www.universityoffashion.com/, Accessed on date 30 October, 2020 